\title{
SAMUEL WILLIAM NORTH, M.R.C.S.
}

Mr. North, a member of the Association since 1869, held sereral officos connected with asylums for the insane. One was that of visiting medical officer to The Retreat, York. He was also medical visitor to private asylume in the North Riding of the county. He was a highly intelligent and thoughtful observer of mental disorders, and an original thinker in many branches of medicine and social science. He studied at the York School of Medicine, famons in its day, and which had the advantage, in the forties, of Dr. Laycock's philosophical teaching. From this school emanated Dr. Hughlings Jackson, Mr. Jonathan Hutchinson, Dr. Needham, and others. Mr. North was senior surgeon to the York Dispensary, Medical Oficer of Health, York Urban District, and surgeon to the York Union Workhouse. He entertained a strong opinion that workhouses, if well managed and provided with a lunaoy ward, were amply sufficient for a largo number of the insane, and, indeed, that the patients are infinitely more comfortable than in palatial county asylums. No one could visit the workhouse under his care without being largely of his opinion. "The experience of numerous workhouses," he observes, in the "Dictionary cf Prychological Medicine," " has abundantly shown that the wants of a belpless imbecile or chronic dement may be well and chesply met in a well-managed workhouse. It seems most probable that in the near future some effort will be made to more largely utilize our workhouses, or other economically.conducted institutions, as a relief to the over-burdened asylums, than has bitherto been done."

In the Journal for July, 1882 (p. 313), will be found an elaborate paper by Mr. North on "The Treatment of l'auper Lunatios," a paper read before a Poor Law Conference for Yorkshire, held at York, under the presidenoy of the Right Hon. James Stansfeld, M.P. In this paper he contended (1) that it is the duty of Boards of Guardians to provide for all their sick, including lunatios, whether in asylums or elsewhere, such treatment as they may require, and that for cases of acute and curable insanity asylums afford the best provision (2.) That for chronic and incurable cases it is their duty to reduce the cost of maintenance to as low a level as is consistent with their proper care and castody. (8.) That the provision of suitable wards and attendants in conneotion with workhouses affords the best and most economical method of providing for the wants of this class. (4.) That some supervision should be exeroised over the class of cases sent to asylums. (5.) That all panper lunaoy, certainly that in workhouses, should be placed under the direct control of the Locel Government Board, who, by the aid of skilled inspection, should bring the management of pauper lunacy into harmony with the principles of the poor law, having due regard to the requirements of the sick on the one hand and the interests of the ratepayers on the other.

Mr. North contributed a valuable article on "Insanity and Crime" to the "Journal of Mental Science " in 1886. "The contention of this paper," he writes, " is that the law of responsibility in criminal cases is wrong in fact, and contrary to knowledge and experience ; that the result is to introdnce great ancertainty into the administration of justice, especially where persons are charged with murder; and that the panishment justly due to the greatest of crimes is rendered halting and uncertain. I contend that the ruling of judges ahould be altered in accordance with knowledge and experience, so that the whole truth may be submitted to the jury; that this modification would restore the certainty of punishment in a department of our criminal law which of late years has become uncertain."

Mr. North was born at Birstwith, near Knaresborough, and was young when he settled in York, where he resided to the time c f his death, aged 69, on the 16th June, sincerely regretted by those who knew him. 